Mathematische Mußestunden 

PROF. DR. HERMAN N S H U B E R T

\title{
Mathematische Mußestunden
}

Eine Sammlung von Geduldspielen, Kunststücken

und Unterhaltungsaufgaben mathematischer Natur

\author{
Neubearbeitet von \\ J OACHIM ERLEBACH
}

Zwölfte Auflage

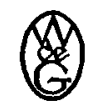

WALTER DE GR UYTER \& C O vormals $G$. f. Göschen'sche Verlagshandlung · f. Guttentag, Verlagsbuchhandlung - Georg Reimer - Karl f. Trübner Veit \& Comp.

Berlin 1964 


\section{Ludendo Discimus}

Leibniz

(C)

Copyright 1964 by Walter de Gruyter \& Co., vormals G. J. Goschen'sche Verlagshandlung J. Guttentag, Verlagsbuchhandlung - Geotg Reimer - Karl J. Trübnet - Veit \& Comp. Berlin 30. - Alle Rechte, einschl. der Rechte der Herstellung von Photokopien und Mikrofilmen, vom Verlag vorbehalten. - Archiv-Nr. 1224641. - Satz und Druck: Waltet de Gruyter \& Co. Berlin 30. - Printed in Germany. 